\title{
A study of meconium stained amniotic fluid, its significance and early maternal and neonatal outcome
}

\author{
Devangi Desai*, Kishor Chauhan, Sharda Chaudhary
}

\begin{abstract}
Department of Obstetrics and Gynecology, SBKS Medical Institute and Research Centre, Pipariya, Ta-Waghodia, Vadodara-391760, Gujarat, India

Received: 18 March 2013

Revised: 25 March 2013

Accepted: 14 April 2013

*Correspondence:

Dr. Devangi Desai,

E-mail: dr.devangi@gmail.com

(C) 2013 Desai D et al. This is an open-access article distributed under the terms of the Creative Commons Attribution License, which permits unrestricted use, distribution, and reproduction in any medium, provided the original work is properly cited.
\end{abstract}

\begin{abstract}
Background: Fetal well-being has traditionally been evaluated on the basis of fetal activity fetal heart and presence of meconium in liquor amnii in vertex presentation. The significance of meconium claimed to vary between its entirely being physiological to a sign of fetal distress. Passage of meconium is considered physiological exhibiting sign of fetal maturity on one hand \& a sign of fetal distress and response to hypoxic insult on the other hand.

Methods: The present study is a case-control study of meconium stained amniotic fluid, its significance and early maternal and neonatal outcome and was carried out in the department of Obstetrics \& Gynecology, Dhiraj General Hospital, Pipariya during April 2011 to March 2012.

Results: The incidence of passage of meconium was relatively higher in patients with pregnancy induced hypertension (20\%) and pregnancy beyond 40 weeks (14.66\%). Amongst the cases $28.66 \%$ patients had an abnormal fetal heart pattern and $12 \%$ had a variable fetal heart pattern whereas in controls the values were $8 \%$ and $3.33 \%$ respectively. The total number of patients with meconium aspiration was $18 \%$ whereas those with meconium aspiration syndrome were $6 \%$.

Conclusions: Meconium passage still remains an enigma to the obstetrician. However, as shown in the study, thick meconium or thin are indicative of fetal distress. If modern management is based on the understanding of underlying pathophysiology of meconium passage than the harmful effect of meconium can certainly be lessened.
\end{abstract}

Keywords: Meconium, Fetal distress, Amniotic fluid

\section{INTRODUCTION}

Fetal well-being has traditionally been evaluated on the basis of fetal activity fetal heart and presence of meconium in liquor amnii in vertex presentation.

The significance of meconium claimed to vary between its entirely being physiological to a sign of fetal distress. Passage of meconium is considered physiological exhibiting sign of fetal maturity on one hand \& a sign of fetal distress and response to hypoxic insult on the other hand. Clear amniotic fluid on the other hand is considered reassuring. Amniotomy in labour is also commonly performed to detect meconium where fetal heart rate is unsatisfactory. If meconium stained amniotic fluid (MSAF) is found, then continuous fetal heart rate monitoring (Cardiotocography CTG) is required for fetal well being. ${ }^{3-5}$

In recent years there is a dramatic fall in the rates of stillbirths and neonatal deaths due to improvement in antenatal and intra natal care in cases of passage of meconium. 
Walker stated that when meconium is passed, the oxygen saturation in umbilical vein is at or below $30 \% .^{2}$ It has been proposed by Eastman that anoxia weakens the action of rectal sphincters leading to passage of meconium.

Meconium Aspiration Syndrome (MAS) is a common problem encountered during delivery. The presence of meconium stained amniotic fluid (MSAF) is a serious sign of fetal compromise, which is associated with an increase in perinatal morbidity. MSAF was noted in approximately $12 \%$ of all deliveries. Meconium aspiration syndrome (MAS) was noted in 5\% of these infants and more than $4 \%$ of MAS infants died accounting for $2 \%$ of all perinatal deaths. ${ }^{1}$ Fortunately, only $5 \%$ of neonates born through MSAF develop MAS. ${ }^{2}$

MAS is more frequently seen in post term pregnancy or in growth restricted fetuses. An increased incidence of meconium passage into the amniotic cavity is also noted in the presence of feto-maternal stress factors such as hypoxia and infection, independent of fetal maturation. ${ }^{6}$ Factors such as placental insufficiency, maternal hypertension, pre-eclampsia, oligohydramnios or maternal drug abuse (tobacco or cocaine) also result in, in-utero passage of meconium. ${ }^{7}$

The present study will help in modification of obstetric decisions (like early induction of labour after 37 weeks gestation, caesarean or instrumental deliveries) in the light of the results, and also generalizing the modified procedures in various organizations or elsewhere.

\section{METHODS}

\section{Aims of the study}

1. To observe the obstetric outcome in clinical cases of meconium stained amniotic fluid.

2. To observe the effect of thin and thick meconium, early and late meconium on obstetric and neonatal outcome

3. To know the association of maternal and fetal factors and passage of meconium and to assess the importance of the same as predictor of neonatal outcome.

\section{Protocol and study period}

After clearance from departmental committee and ethics committee the work was started. Time Scale: $1 \frac{1}{2}$ year.

The present study is a case-control study of meconium stained amniotic fluid, its significance and early maternal and neonatal outcome was carried out in the department of Obstetrics \& Gynecology, Dhiraj General Hospital, Pipariya during April 2011 to March 2012.

During the specified study period, 150 cases of meconium stained amniotic fluid were enrolled in the study at random keeping following selection criteria:

1. Full Term Live Pregnancy

2. Singleton Pregnancy

3. Vertex Presentation

4. Meconium staining of amniotic fluid is detected after rupture of membranes.

\section{Selection criteria for control cases:}

1. Full term live pregnancy

2. Singleton pregnancy

3. Vertex presentation

4. Clear liquor amnii

Primigravida case- Primigravida control

Multigravida case- gravidity of control may be plus or minus 1

All the information regarding cases and controls were noted in systemic way in the proforma

The follow-up observation for cases and control were made as under

1. At the time of discharge of mother and baby $\left(7^{\text {th }}\right.$ day).

2. 1 month after the discharge.

3. 3 months after discharge

Chi-square test was used for statistical analysis of the data.

\section{RESULTS}

Table 1: Analysis according to high risk conditions.

\begin{tabular}{|l|lllll|}
\hline \multirow{4}{*}{ Anaemia } & & Case & $\%$ & Control & $\%$ \\
& Moderate & 41 & 65.08 & 63 & 67.02 \\
\cline { 2 - 6 } & Severe & 19 & 31.66 & 31 & 32.98 \\
\cline { 2 - 6 } & Total & 60 & 42.00 & 94 & 62.67 \\
\hline \multirow{3}{*}{ PIH } & Mild & 21 & 70.00 & 13 & 76.47 \\
\cline { 2 - 6 } & Severe & 9 & 30.00 & 4 & 23.53 \\
\cline { 2 - 6 } & Total & 30 & 20.00 & 17 & 11.33 \\
\hline
\end{tabular}




\begin{tabular}{|lllll|}
\hline Eclampsia & 3 & 2 & 2 & 1.33 \\
\hline Pregnancy $>40$ weeks & 22 & 14.66 & 11 & 7.33 \\
\hline Prom & 6 & 4 & 4 & 2.66 \\
\hline Oligohydramnios & 9 & 6 & 6 & 4 \\
\hline IUGR & 7 & 4.66 & 5 & 3.33 \\
\hline PREV CS & 10 & 6.66 & 9 & 6 \\
\hline Abruptio placenta & 3 & 2 & 2 & 1.33 \\
\hline
\end{tabular}

In this study it was noted that the incidence of passage of meconium was relatively higher in patients with pregnancy induced hypertension (20\%) and pregnancy beyond 40 weeks $(14.66 \%)$.

Table 2: Distribution of cases according to fetal heart rate pattern.

\begin{tabular}{|c|c|c|c|c|}
\hline $\begin{array}{l}\text { Fetal heart } \\
\text { pattern }\end{array}$ & Case & $\%$ & Control & $\%$ \\
\hline $\begin{array}{l}\text { Normal } \\
\text { baseline } \\
\text { FHR }\end{array}$ & 89 & 59.33 & 133 & 88.66 \\
\hline $\begin{array}{l}\text { Outside } \\
\text { normal } \\
\text { baseline } \\
\text { FHR }\end{array}$ & 43 & 28.66 & 12 & 8 \\
\hline Variable FHR & 18 & 12 & 5 & 3.33 \\
\hline
\end{tabular}

In this table, it was noted that amongst the cases $28.66 \%$ patients had an abnormal fetal heart pattern and $12 \%$ had a variable fetal heart pattern whereas in controls the values were $8 \%$ and $3.33 \%$ respectively. This is highly significant suggesting that patients with meconium stained liquor definitely have an abnormal fetal heart rate pattern.

Table 3: Character of meconium in relation with fetal heart rate pattern.

\begin{tabular}{|llll|}
\hline Thin & \multicolumn{3}{c|}{ Thick } \\
\hline Alone & $\begin{array}{l}\text { With } \\
\text { abnormal } \\
\text { FHR pattern }\end{array}$ & Alone & $\begin{array}{l}\text { With } \\
\text { abnormal } \\
\text { FHR pattern }\end{array}$ \\
\hline $72(48 \%)$ & $9(6 \%)$ & $17(11.33 \%)$ & $52(34.66 \%)$ \\
\hline
\end{tabular}

Here it was observed that $34.66 \%$ patients with thick meconium had an abnormal FHR pattern whereas only $6 \%$ of patients with thin meconium had an abnormal FHR pattern.

Table 4: Analysis according to mode of delivery.

\begin{tabular}{|c|c|c|c|c|}
\hline \multirow{2}{*}{$\begin{array}{l}\text { Mode of } \\
\text { delivery }\end{array}$} & \multicolumn{2}{|c|}{ MSAF } & \multicolumn{2}{|c|}{ Control } \\
\hline & No & $\%$ & No & $\%$ \\
\hline Find & 47 & 31.33 & 86 & 57.33 \\
\hline LSCS & 84 & 56 & 52 & 34.66 \\
\hline Vacuum & 5 & 3.33 & 3 & 2.00 \\
\hline Forceps & 14 & 9.33 & 9 & 6.00 \\
\hline Total & 150 & 100.0 & 150 & 100.0 \\
\hline
\end{tabular}

Table 5: Incidence of meconium aspiration.

\begin{tabular}{|lll|}
\hline $\begin{array}{l}\text { Total no. } \\
\text { of MSAF }\end{array}$ & $\begin{array}{l}\text { Total no. of } \\
\text { meconium aspiration }\end{array}$ & $\begin{array}{l}\text { Percentage } \\
(\%)\end{array}$ \\
\hline 150 & 27 & 18 \\
\hline
\end{tabular}

Table 6: Incidence of Meconium Aspiration Syndrome (MAS).

\begin{tabular}{|lll|}
\hline $\begin{array}{l}\text { Total no. of } \\
\text { MSAF }\end{array}$ & $\begin{array}{l}\text { Total no. of } \\
\text { MAS }\end{array}$ & $\begin{array}{l}\text { Percentage } \\
(\%)\end{array}$ \\
\hline 150 & 27 & 18 \\
\hline
\end{tabular}

In this study the total number of patients with meconium aspiration was $18 \%$ whereas those with meconium aspiration syndrome was $6 \%$

Table 7: Distribution of cases according to morbidity and mortality.

\begin{tabular}{|lllll|}
\hline Neonatal morbidity & Case & Percentage (\%), $\mathbf{n = 1 5 0}$ & Control & Percentage (\%), $\mathbf{n = 1 5 0}$ \\
\hline $\mathrm{O}_{2}$ supplementation & 27 & 18.00 & 16 & 10.67 \\
\hline Endotracheal intubation & 13 & 8.67 & 15 & 10.00 \\
\hline Ventilator support & 6 & 4.00 & 4 & 2.67 \\
\hline Antibiotics & 16 & 10.67 & 21 & 14.00 \\
\hline Neonatal death & 17 & 11.33 & 10 & 6.67 \\
\hline Inotropes & 6 & 4.00 & 2 & 1.33 \\
\hline Screen positive & 10 & 6.67 & 3 & 2.00 \\
\hline Culture positive & 14 & 9.33 & 10 & 6.67 \\
\hline
\end{tabular}




\section{DISCUSSION}

Most of the centers in our country lack facilities for electronic fetal heart rate monitoring and fetal scalp blood studies. Under such circumstances only clinical evaluation of cases with meconium stained amniotic fluid in necessary. It is therefore necessary to re-examine the importance of clinical methods and apply them to judge the fetal hypoxia and prevent its long-term sequel.

Till such time that better strategies for management of meconium stained neonates are outlined by further studies, the best course would be careful intrapartum fetal heart rate monitoring and other measures to prevent fetal asphyxia.

Immediate airway management, need for suction and intubation should be guided by the state of the newborn, rather than the presence of meconium. Although the direct and indirect effects remain uncertain, meconium stained amniotic fluid is consistently identified as a predictor of maternal and perinatal complications. ${ }^{1}$

Meconium passage still remains an enigma to the obstetrician. However, as shown in the study, thick meconium or thin are indicative of fetal distress. If modern management is based on the understanding of underlying pathophysiology of meconium passage then the harmful effect of meconium can certainly be lessened.

Funding: No funding sources Competing interests: None declared

Ethical approval: The study was approved by the Institutional Ethics Committee

\section{REFERENCES}

1. Ahanya SN, Lakshmanan J, Morgan BL, Ross MG. Meconium passage in utero: mechanism, consequences, and management. Obstet Gynecol Surv 2004;60:45-56.

2. Cleary GM, Wiswell TE. Meconium-stained amniotic fluid and the meconium aspiration syndrome: an update. Pediatr Clin North Am 1998;45:511-29.

3. Xu H, Mas-Calvet M, Wei SQ, et al. Abnormal fetal heart rate tracing patterns in patients with thick meconium staining of the amniotic fluid: association with perinatal outcomes. Am J Obstet Gynecol 2009;200:283.e1-283.e7.

4. Gee H. Routine intrapartum care: an overview. In: Luesley DM, Baker PN. Obstetrics and gynecology: an evidence based text for MRCOG, 2nd edition. Hodder Arnold 2010:287-95.

5. NICE. Intra-partum care. Clinical Guideline 55. London: National Institute for Health and Clinical Excellence, 2007.

6. Naveen S, Kumar SV, Ritu S, Kushia P. Predictors of meconium stained amniotic fl uid: a possible strategy to reduce neonatal morbidity and mortality. J Obstet Gynecol India 2006;56:514-7.

7. Shaikh EM, Mehmood S, Shaikh MJ. Neonatal outcome in meconium stained amniotic fluid- One year experience. J Pak Med Assoc 2010;60:711-4.

DOI: $10.5455 / 2320-1770$. ijrcog20130616

Cite this article as: Desai D, Chauhan K, Chaudhary S. A study of meconium stained amniotic fluid, its significance and early maternal and neonatal outcome. Int J Reprod Contracept Obstet Gynecol 2013;2:190-3. 